\title{
JOSEF STEFAN AND HIS CONTRIBUTIONS TO HEAT TRANSFER
}

\author{
John Crepeau \\ Department of Mechanical Engineering \\ University of Idaho \\ 1776 Science Center Drive \\ Idaho Falls, Idaho 83402 USA \\ Phone: (208)282-7955 \\ Fax: (208)282-7950 \\ Email: crepeau@uidaho.edu
}

\begin{abstract}
Josef Stefan was a professor of physics at the University of Vienna between 1863 and 1893. During his time in Vienna he was a fruitful researcher in many scientific fields, but he is best known for his work in heat transfer. He was a gifted experimentalist and theoretician who made contributions to conduction, convection and radiation heat transfer. Stefan was the first to accurately measure the thermal conductivity of gases, using a device he invented called the diathermometer. He also determined the diffusion of two gases into each other, a process now known as Maxwell-Stefan diffusion. His work provided experimental verification of the newly formulated kinetic theory of gases published by the great Scottish physicist James Clerk Maxwell.

Stefan also experimentally studied the motion of gases induced by evaporation along a liquid surface, a phenomenon known as Stefan flow. In addition, Stefan received data from various expeditions on ice formation in the arctic seas. From that solid/liquid phase change data, he formulated solutions to the moving boundary problem, now called the Stefan problem.

The work for which he is most famous is the $\mathrm{T}^{4}$ radiation law which he deduced from the experimental work of a number of investigators. However, his theory was not widely accepted until his former student, Ludwig Boltzmann, derived the same relation from first principles. In their honor, the $\mathrm{T}^{4}$ radiation equation is called the Stefan-Boltzmann law.

Despite his varied contributions, little is known about Stefan the man. This paper gives some details on his life and describes the seminal work he performed in broad areas of heat transfer.
\end{abstract}

\section{BRIEF HISTORY}

Josef Stefan (Fig. 1) was born on 24 March 1835, to poor, peasant parents, Aleš Stefan, who was a miller and baker, and Marija Startinik, a maidservant, in the village of St. Peter on the outskirts of Klagenfurt, in modern-day Austria [1]. At the time of his birth, Klagenfurt was part of the multiethnic AustroHungarian empire, and his birthplace was home to a large Slovenian population. Stefan grew up speaking Slovene at home and learned German at school, where he distinguished himself academically. He went on to study at the local Gymnasium where he taught himself mathematics and physics from textbooks [2].

Stefan was a devout Roman Catholic and seriously considered joining the Benedictine Order to become a priest, but instead enrolled at the University of Vienna in 1853. At the University he chose to study mathematics and physics and learn from faculty who could expound what he studied earlier. He graduated in 1857 and taught physics for pharmacy students. He showed an aptitude for research, and published his first paper, "General equations of oscillatory motion," [3] in the same year that he graduated. At this time he came under the influence of Carl Ludwig, a professor of physiology, who noted Stefan's technical ability. Under the tutelage of Prof. Ludwig, who was the head of the Physiological Institute at the University of Vienna, Stefan refined his experimental abilities as they studied fluid flow in tubes, an analogy to blood flow in vessels. In 1858, Stefan took and passed his doctoral exam, which until 1872 in Austria, was all that was required to receive a doctorate [4]. No dissertation was necessary, although Ludwig served as his de facto mentor. 


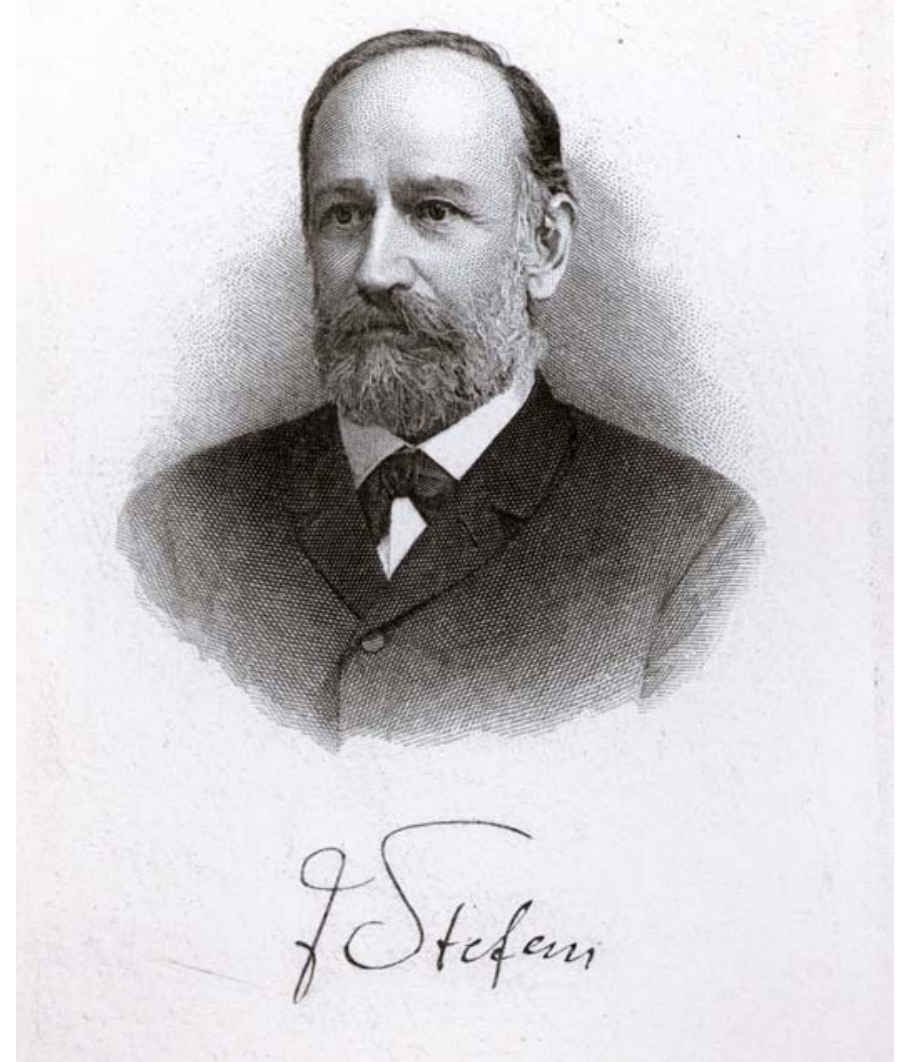

Figure 1. Portrait of Josef Stefan, taken in the late 1880s (Courtesy of the Austrian Academy of Sciences).

Upon receipt of his doctorate, Stefan was appointed a Privatdozent, the lowest academic rank, at the Physiological Institute, and published four more papers, including one on pressure measurements of flow in tubes, with his mentor Ludwig. Despite his indebtedness to Ludwig, Stefan remained a physicist at heart. In 1863, Stefan was appointed an ordinary professor, the highest academic rank, of mathematics and physics. He then accepted a position at the Institute of Physics at the University of Vienna (Fig. 2), which at that time was under the directorship of Andreas von Ettinghausen. When von Ettinghausen stepped down two years later due to poor health, Stefan was appointed director over the young Ernst Mach.

Throughout his career, Stefan served in many administrative positions at the University of Vienna, including Dean of the Philosophical Faculty (1869-1870) as well as Rector (1876-1877). He was also Secretary and Vice-President of the Austrian Academy of Sciences. On top of his administrative abilities, Stefan was an excellent teacher and mentor. He maintained a warm, collegial and inspiring research atmosphere at the Institute. His lectures were clear and animated, and drew a large number of students. One of his early students, appearing at the Institute just after Stefan became director, was Ludwig Boltzmann. Boltzmann wrote of his mentor Stefan, "He used the tools of advanced mathematics and understood how to present the most difficult developments in the clearest and most lucid form without ever having to resort to mathematical formalism...[he] never tried to flaunt [his] mental superiority. [His] uplifting humor, which turned the most difficult discussion into an entertaining game for the student, made such a deep impression on me.” [5] Besides Boltzmann, another of Stefan's students went on to great fame, albeit not in physics. Sigmund Freud, the psychoanalyst, took classes from Stefan as part of his medical studies. Stefan was a "profoundly influential teacher" for Freud, because Stefan emphasized the natural and necessary interdependence of theory and practice, principles that became hallmarks of Freud's work [6].

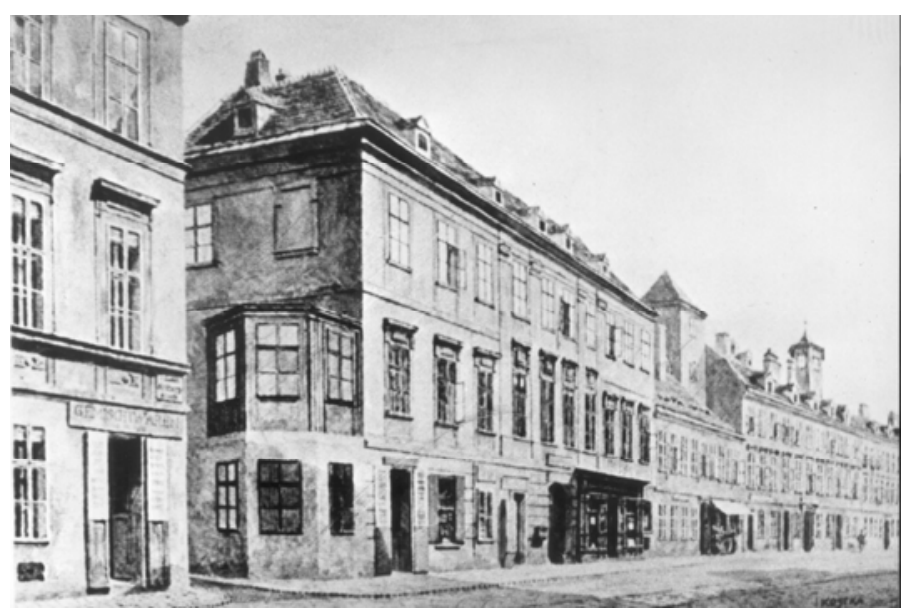

Figure 2. Erdbergstrasse 15, location of the Institute of Physics building of the University of Vienna, where Stefan served as Director from 1865 until his death in 1893 (Courtesy of the Austrian Academy of Sciences).

Stefan published papers in mathematics, mechanics, acoustics, optics, and electrodynamics. In this article, I will focus only on his main contributions to heat transfer. Sometimes, in a particular area of study, Stefan published his work over a number of years, so a chronological approach to presenting his contributions would seem erratic and haphazard. Therefore, this paper is divided into the three main areas of heat transfer, conduction, convection, and radiation, and his contributions to each subfield.

\section{CONDUCTION HEAT TRANSFER}

\section{Measuring the Thermal Conductivity of Gases}

In Stefan's day, it was a relatively straightforward procedure to measure the thermal conductivity of solids and liquids, but gases were another matter. In fact, many renowned scientists debated whether or not gases could even conduct heat. There were many unsuccessful attempts at measuring the thermal conductivity of a gas, primarily because of the heat loss in the system and the convection currents that can form [7]. In 1860, James Clerk Maxwell, then at Marischal College, Aberdeen, 
published the first in a series of papers on what would be known as the kinetic theory of gases. The paper was not particularly well-received in England or continental Europe, in part because of the difficulty of the theory. Stefan was an early advocate and encouraged Boltzmann to study Maxwell's work. In his theory, Maxwell determined a theoretical value for the thermal conductivity of a gas and gave its dependence on temperature and pressure. However, Maxwell also wrote, "It would be almost impossible to establish the value of the conductivity of a gas by direct experiment, as the heat radiated from the sides of the vessel would be far greater than the heat conducted through the air, even if currents could be entirely prevented." [8]

Realizing that convection currents were a large hurdle to overcome, and after a few false starts, Stefan [9] devised an instrument which he called a diathermometer (Fig. 3). In his design, Stefan placed the gas to be measured in a thin gap between two concentric cylinders. Within the inner cylinder, Stefan injected the same gas, which was connected to a manometer. To calculate the thermal conductivity, Stefan equated the total heat transfer by conduction through the candidate gas to the change of energy absorbed by the gas [10],

$$
-k A_{c} \frac{\theta}{\Delta x} d t=m c_{v} d \theta
$$

After rearranging and integrating, he found,

$$
\frac{\theta}{\theta_{0}}=\exp \left(\frac{-k A_{c}}{m c_{v} \Delta x} t\right)
$$

where $\theta_{0}$ was the initial temperature difference between the diathermometer and the temperature bath. For an ideal gas at constant volume, the relative change in the temperature is equal to the relative change in the pressure, so,

$$
\frac{\Delta p}{\Delta p_{0}}=\exp \left(\frac{-k A_{c}}{m c_{v} \Delta x} t\right)
$$

Stefan then placed the cylinders of the diathermometer into a temperature bath and measured the pressure as a function of time. Once the pressure change is measured it is a straightforward calculation using Eq. 3 to determine the thermal conductivity. For air, Stefan found the thermal conductivity to be $k=0.0234 \mathrm{~W} / \mathrm{mK}$, an $11 \%$ difference from the presently accepted value of $k=0.0263 \mathrm{~W} / \mathrm{mK}$ (at 300K). Using Maxwell's kinetic theory of gases, the thermal conductivity of air can be calculated to be $k=0.0218 \mathrm{~W} / \mathrm{mK}$. Later, Stefan [11] measured the thermal conductivities of other gases, including nitrous oxide, methane, and carbon monoxide.

Besides the actual measurement of thermal conductivity, he showed that it did not vary with the pressure, in accordance with Maxwell's kinetic theory. Boltzmann described his mentor's device as, "fantastically simple," and that it measured the thermal conductivity, "with an exactness not previously thought possible," and "it proved to lend glowing support to every other prediction of kinetic theory."[5] Strnad and Vengar [10] showed how this simple device could be built and used as an experiment in a student laboratory.

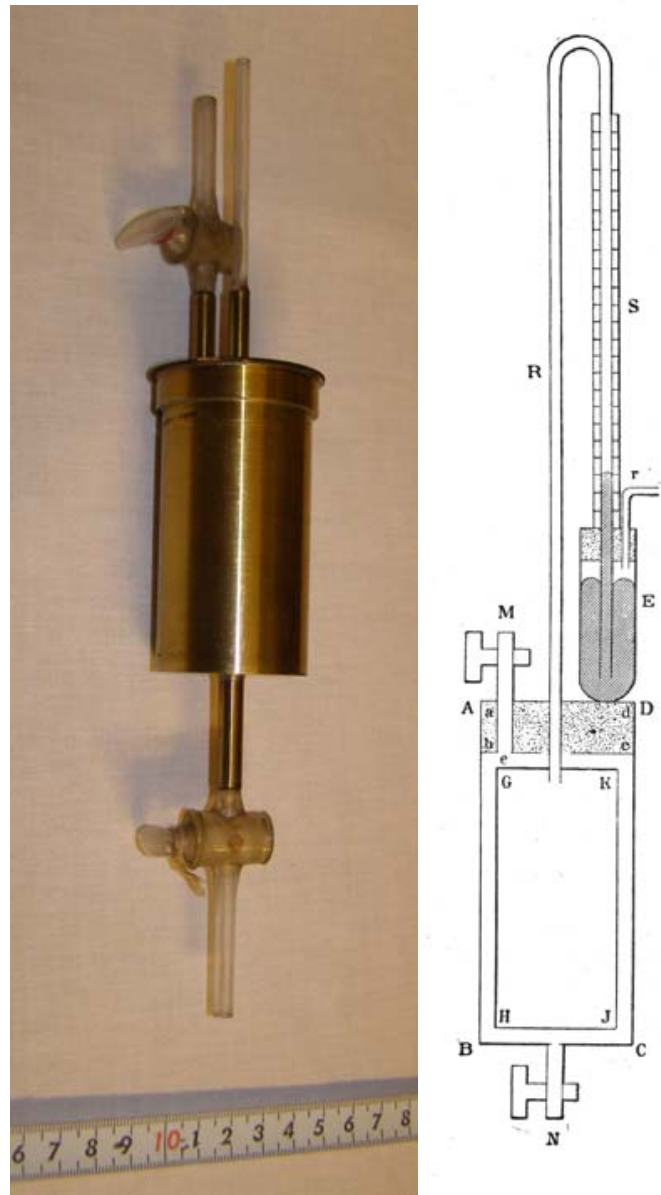

Figure 3. (Left) Picture of the diathermometer used by Stefan to make thermal conductivity measurements of gases (Photo by the author). (Right) Schematic of the diathermometer. The gas is bled into the cavity e through valve $\mathrm{M}$, between concentric cylinders ABCD and GHJK. The cylinders are then placed in a temperature bath and the change of pressure is measured as a function of time (Courtesy of the Austrian Academy of Sciences).

\section{Diffusion}

At the Institute, Stefan worked with another scientist, Josef Loschmidt, who, among other things, was interested in studying the diffusion of particles in gases and liquids, and published his own work [12] in this area. Loschmidt placed gases of different densities in a vertical glass tube, with the lower density gas being on top, and after a certain period of time measured how much gas had diffused into the other. Maxwell remarked that Loschmidt had, "recently made a series of most valuable and accurate experiments on the interdiffusion of gases in a vertical tube, from which he has deduced the coefficient of diffusion of ten pairs of gases. These results I consider to be the most valuable hitherto obtained as data for the construction of a molecular theory of gases.” [13] Stefan was not above sarcastic critiques of his colleague. After listening to Boltzmann and Loschmidt debate a particularly 
bizarre scientific proposition, Stefan remarked, "Now I know why your attempts with the large glass tubes in the basement failed so miserably." [14]

Stefan's first paper on diffusion [15] was published in 1871, which expanded Maxwell's kinetic theory of gases, applied Loschmidt's data to his theory, and included his own experimental data. Stefan described the diffusion process in terms of hydrodynamic laws, and he understood that diffusion can give rise to convective motion in the fluid. [16] This type of diffusion called either Stefan-Maxwell diffusion [17] or Maxwell-Stefan diffusion [18] is driven by a gradient in the chemical potential,

$$
-\nabla \mu_{i}=R T x_{j}\left(\frac{\mathrm{v}_{i}-\mathrm{v}_{j}}{D_{i j}^{M S}}\right)
$$

which differs from Fick's Law,

$$
N_{i}^{\prime \prime}=-D_{i j} \frac{\partial C_{i}}{\partial y}
$$

that states diffusion is driven by a gradient in the species concentration. The following year, Stefan published a paper [19] relating the kinetic theory and the diffusion of gases. In the paper he derived an expression for the diffusion coefficient based on modeling the gas molecules as elastic spheres. He showed that the mean free path and the internal friction (viscosity) could be calculated from the diffusion coefficient. Stefan then expanded his diffusion studies to investigate those processes in liquids. In 1878 he published experimental data [20] on the diffusion of carbon dioxide in water and alcohol, a forerunner of carbonated drinks. More than a decade later, just four years before his death, he published a study comparing diffusion in acids and bases [21].

Stefan's thermal conductivity work, and the combined efforts of Stefan and Loschmidt in diffusion did more than just provide experimental data in specialized areas of science. Perhaps the greatest, yet unheralded contribution of their combined work was to provide experimental verification of the fledgling kinetic theory of gases as propounded by Maxwell and Boltzmann. Not only did the data match the theory, but the parametric behavior of the variables agreed with the equations derived by Maxwell. He noted, "Prof. Stefan of Vienna, by means of a very ingenious method, has obtained the first experimental determination of the conductivity of air. The result is, as he says, in striking agreement with the kinetic theory of gases...The numerical results obtained by Prof. Loschmidt...agree in a very remarkable manner with the formula derived from the kinetic theory.” [13]

\section{CONVECTION HEAT TRANSFER}

Flow Driven by Phase Change

In conjunction with his diffusion experiments, Stefan investigated the effect of evaporation on fluid movement and mixing [22]. He used ether and carbon disulfide as working fluids and determined their evaporation rates in air and hydrogen. As part of his analysis, he approximated the evaporation process as the diffusion of the vapor of the working fluids through the air (or hydrogen), and determined the diffusion coefficients. In a later paper [23], Stefan showed that the equations of evaporation from a fluid in a circular disk are similar to those of force and potential lines in an electric field of a thin, infinitely long conducting plate. His main result was that the evaporation rate was proportional to the square root of the fluid surface area.

Stefan's work on evaporation became the inspiration for the area of study of fluid motion driven by phase change, called Stefan flow [24]. Stefan flow describes fluid flow as the result of processes as diverse as evaporation [25], condensation, chemical reaction [26], sublimation, ablation, absorption, desorption and electrolytic solutions [27]. The average velocity of the evaporating gases has been called the Stefan velocity [28] and is given by,

$$
V_{S}=-\frac{D_{V}}{p_{2}} \frac{d p_{1}}{d x}
$$

Here $D_{V}$ is the diffusion coefficient of the vapor in the gas, and $p_{1}$ and $p_{2}$ are the partial pressures of the vapor and carrier gases respectively.

Usually the effect of the Stefan velocity is quite small, and for many years, its effect was neglected. Recently the effect has been taken into account for fluid motion driven by phase change.

\section{Solid/Liquid Phase Change}

As a high-ranking, well-regarded member of the Austrian Academy of Sciences, Stefan was aware of the scientific work that was carried out in Vienna, and he sat in on lectures from visiting scientists. From 1872 to 1874, the Austro-Hungarian Empire sponsored an expedition to the polar ice caps [29], presumably to find a passage through the Arctic. During this trip, they took air temperature measurements, and recorded ice growth rates. The leader of the expedition, Karl Weyprecht and co-leader Julius von Payer reported their findings to the academy in 1876. We surmise that this is where Stefan first took interest in the solid/liquid phase change problem. This particular problem presented difficulties since the thickness of the solid layer was time-dependent. Later, Stefan became aware of ice growth rates data taken separately by British and German explorers during earlier expeditions [30].

With this data in hand, Stefan attempted to find an analytical solution to this so-called moving boundary problem. Although Stefan did not know it, this same problem had been investigated previously by Lamé and Clapeyron [31] and Neumann [32]. Stefan began his analysis by using a conservation of energy model at the solid/liquid interface and assuming a linear temperature profile within the ice. $\mathrm{He}$ showed from this simple model that the square of the ice thickness was a linear function of time,

$$
h^{2}(t)=\frac{2 k \Delta T}{\rho \lambda} t
$$


Using this model, Stefan compared his theory with the experimental data and found rough agreement between the two. Valid comparisons were hampered by the fact that there were not accurate values for the thermal conductivity of ice. However, Stefan was encouraged that his simple model did match the trends of the data. Realizing that his linear temperature model would not be sufficiently accurate, he defined a time-dependent temperature profile and found,

$$
h^{2}(t)=\frac{2 k}{\rho \lambda} \int_{0}^{t} \Delta T d t
$$

which Stefan called the kältesumme [33], or cold sum. With this model he found much better agreement with the experimental data.

After Stefan published his paper, the solid/liquid phase change problem lay dormant for many years. Boltzmann did not mention this work in either of the memorial addresses he gave about Stefan. It wasn't until about a half-century later that researchers became interested in the problem again, and to honor Stefan's work, the solid/liquid phase change problem or moving boundary problem was called the Stefan problem [34]. The Stefan problem, or variants of it, have been an active and fruitful area of research ever since [35]. The primary dimensionless number in these types of problems is the Stefan number,

$$
\text { Ste }=\frac{c_{p} \Delta T}{\lambda}
$$

This ratio was coined by Lock [36] when he used it as a perturbation variable in an asymptotic, approximate solution to the moving boundary problem.

\section{RADIATION HEAT TRANSFER}

Not long after Boltzmann left the Institute of Physics in Vienna for his own position in Graz, Stefan began to look at data relating the amount of energy transferred by radiation and the temperature of the receiving surfaces. It was known at the time that radiant energy was not a linear function of the temperature, and in fact, increased quite drastically as the temperature increased. However, the relation between the radiant energy and the temperature was not known.

In 1817, Dulong and Petit [37] published results from experiments they performed using a spherical bulb in a spherical chamber, and proposed a model for the radiant energy as a function of the temperature to be,

$$
E(T)=\mu a^{T}
$$

where $\mu$ was a constant dependent on the size and material of the body, $a=1.0077$, and $T$ was the temperature in degrees centigrade. The maximum temperature they used in their experiments was only about $300^{\circ} \mathrm{C}$. After analyzing the Dulong and Petit data, Stefan did not feel comfortable with their model and began to look at other relations to fit the data better. He also investigated in detail their experimental set-up and realized that there were significant losses due to conduction in the spherical bulbs. After making adjustments in the data, Stefan proposed a model, and using his original notation gave the formula,

$$
H=A T^{4}
$$

where, "A depends on the size and the surface of the body," which fit the data quite well. Unfortunately, the highest temperature used by Dulong and Petit was relatively low, and the real test of the model would come at much higher temperatures.

Stefan then looked at the results given by Tyndall [38] which gave radiant energy data for platinum wire over a wide temperature range. In his paper, Stefan wrote [39], "From weak red heat (about $525^{\circ} \mathrm{C}$ ) to complete white heat (about $1200^{\circ} \mathrm{C}$ ) the intensity of the radiation increases from 10.4 to 122 , thus nearly twelve-fold (more precisely 11.7). The ratio of the absolute temperature $273+1200$ and $273+525$ raised to the fourth power gives 11.6." (translation from Strnad [40]). This was exactly the result that Stefan needed to verify his model. Stefan then applied his formula to other published data and found that his model gave much better agreement than the Dulong and Petit model. Although Stefan had data at his disposal to do so, he never explicitly calculated a numerical value for his constant of proportionality, $A$ [41]. This is probably because he did not have high confidence in the experimental techniques used to generate the data. He also felt strongly that data should be at low temperatures, as close to absolute zero as possible. Based on the data presented in his paper, it can be determined in a relatively straightforward fashion to be $5.056 \times 10^{-8} \mathrm{~W} / \mathrm{m}^{2} \mathrm{~K}^{4}$.

After comparing his model with data from a variety of sources and gaining more confidence in it, he used it to determine the temperature of the Sun. Some researchers used the Dulong and Petit model and found a relatively low temperature for the Sun. Others used their own methods and found values that were still lower than what was reasonably expected. Stefan applied his $\mathrm{T}^{4}$ model and estimated that the Sun's temperature lies in the range of 5580-5838K. These values gave the first accurate calculation of the temperature of the Sun and fits the currently accepted value of about $5770 \mathrm{~K}$.

Unbeknownst to Stefan, there were a number of errors in the data that he analyzed. Strictly speaking, the $\mathrm{T}^{4}$ radiation law holds only for a perfect blackbody radiator. Platinum is not a perfect emitter, and in all of the data Stefan investigated, emissivities of the materials were never considered. There is also some question about the difference between the radiative energy measured by Dulong and Petit and the currently accepted value. Nevertheless and by happy coincidence, the errors cancelled themselves out so that the radiation law, for which Stefan is most famous, was discovered. Figure 4 is a photograph of a plaque marking the birthplace of Stefan in Klagenfurt, acknowledging him as a discoverer of the radiation law. 


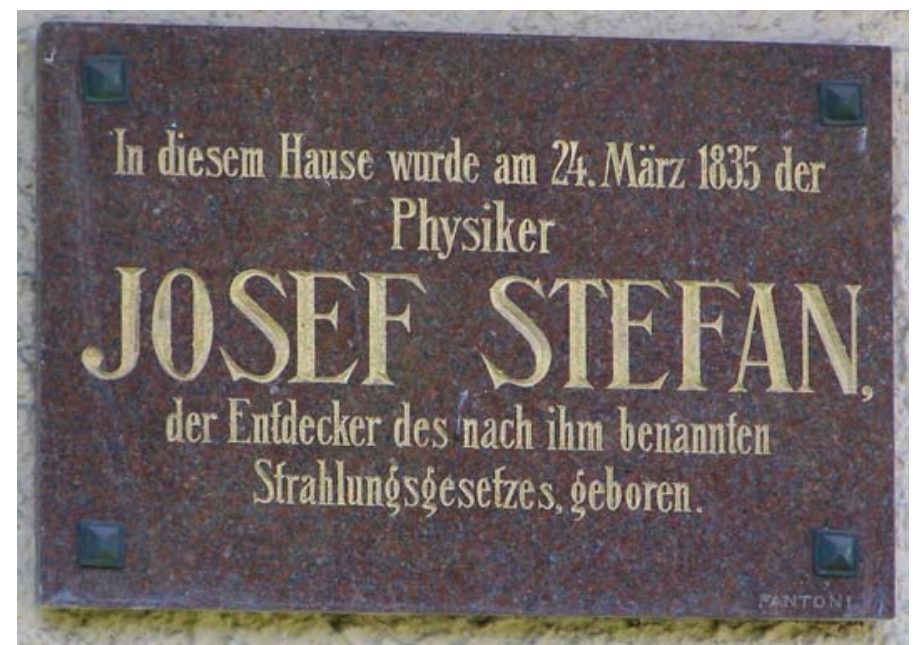

Figure 4. Plaque marking the birthplace of Josef Stefan, in Klagenfurt, Austria. It reads, "In this house, on 24 March 1835, the physicist Josef Stefan, the discoverer for whom the radiation law is named, was born.” (Photo by the author)

Despite the success Stefan's model had in modeling a wide variety of radiant energy data, his work was not widely accepted. The $\mathrm{T}^{4}$ behavior was unprecedented (and still remains a distinctive indicator of radiation heat transfer) and so unusual, that it was difficult for the scientific community to believe. Five years after Stefan's paper was published, Boltzmann, from first thermodynamic principles, derived Eq. (11), which came to be known as the Stefan-Boltzmann law. Like Stefan, Boltzmann never explicitly calculated the proportionality constant between the radiant energy and the temperature to the fourth power, now called the Stefan-Boltzmann constant. Its current value, $5.67 \times 10^{-8} \mathrm{~W} / \mathrm{m}^{2} \mathrm{~K}^{4}$, is about $11 \%$ higher than the value that Stefan could have easily calculated.

Some investigators, most prominently Worthing and Halliday [42], feel that Stefan's contribution to the radiation model was too insignificant and based on erroneous data, such that he didn't even deserve partial credit for its discovery. When discussing Eq. (11), they refer to it only as Boltzmann's law, and the constant as Boltzmann's radiation constant. Presently, their opinion seems to be in the distinct minority. Dougal [43] argues that this judgment is overly harsh. Today, most scientists and engineers continue to refer to these as the Stefan-Boltzmann law and the Stefan-Boltzmann constant.

\section{END OF HIS LIFE}

Stefan published his research nearly up until his death. On 15 December 1892, he presented a paper to the Austrian Academy of Sciences. A few days later he suffered a stroke from which he never recovered, and died on 7 January 1893.

Stefan was a devoted researcher and teacher. His diathermometer is an excellent example of the simple, elegant experiments he designed. He provided guidance and support, as much of the Institute's resources as possible, to let his students design and conduct experiments. He had the ability to adjust his description of complicated scientific principles to suit the capacity of his audience, whether they were experts or laymen. Upon completion of his lectures, he was exhausted and sweated profusely. He was one of the most admired and best liked professors at the University of Vienna. He completely dedicated his life to science and his academic commitments. Despite his fame and contributions, he never travelled outside of Austria to attend scientific conferences or meet with colleagues. To commemorate his contributions, the University of Vienna placed a memorial to him (Fig. 5) in its courtyard arcade. His student Boltzmann gave the dedicatory address [5]. As beautiful as Stefan's memorial is, his greatest legacy is the scientific discoveries he left for posterity.

He was a simple, very private man. Only towards the end of his life did Stefan find a devoted companion, marrying the widow Marija Neumann in 1891. She brought out his lighter side, and he began to joke and laugh as never before, and cared for him until he died. He is buried in Vienna's famed Central Cemetery.

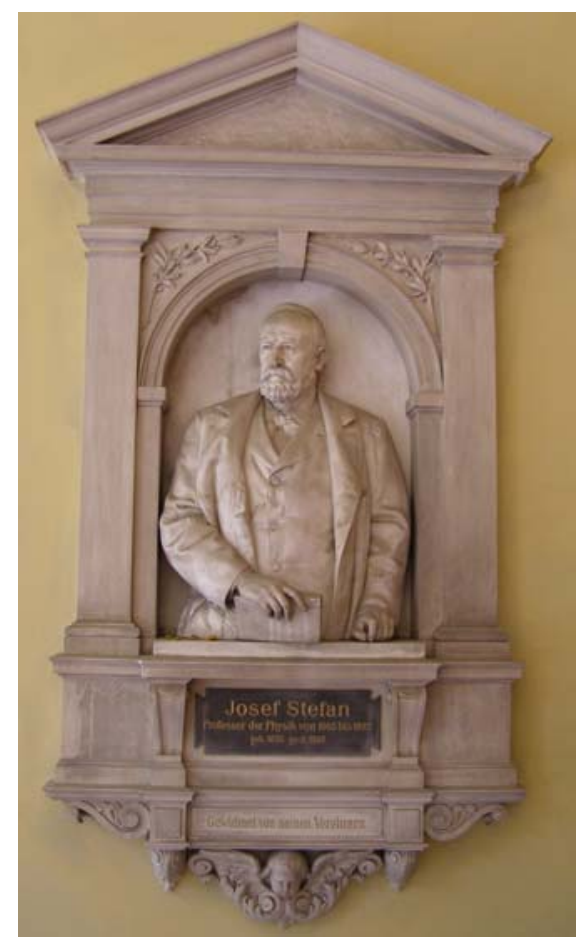

Figure 5. Stefan memorial in the courtyard arcade of the University of Vienna. (Photo by the author)

\section{NOMENCLATURE}

$a-$ constant

A - constant

$A_{c}$ - cross-sectional area

$c_{p}$ - specific heat, constant pressure

$c_{v}$ - specific heat at constant volume

$C_{i}-$ molar concentration, species i 
$D^{M S}$ - Maxwell-Stefan diffusion coefficient

$D_{i j}$ - Fick's diffusion coefficient

$D_{V}$ - diffusion coefficient

$E$ - radiant energy

$h$ - ice thickness

$H$ - radiant energy

$k$ - thermal conductivity

$m$ - mass

$m_{i}-$ molar chemical potential, species i

$N_{i}^{\prime \prime}-$ molar flux, species i

$p$ - pressure

$R$ - ideal gas constant

$t$ - time

$T$ - temperature

$v_{i}-$ velocity of diffusing species i

$V_{S}$ - Stefan velocity

$x_{i}$ - mole fraction, species i

$\Delta x$ - temperature difference

$y$ - distance

\section{Greek}

$\theta$ - temperature difference

$\lambda$ - latent heat

$\mu$ - constant

$\rho$ - density

\section{ACKNOWLEDGMENTS}

I am very grateful to Mrs. Jennifer O'Laughlin from Interlibrary Loans at the University of Idaho for obtaining copies of many of the original documents. Mr. David Lindley sent a copy of Boltzmann's address at the dedication of the Stefan memorial. Mr. Dustin Marshall did an outstanding job of translating many of the articles from German, and I am deeply indebted to him for his efforts. I must also thank my fellow Stefanphile, Dr. Janez Strnad of the University of Ljubljana for his gracious conversations and work on Stefan's life. Prof. Wolfgang Reiter of the University of Vienna provided tremendous assistance while searching the archives in Vienna. The doctoral dissertation of $\mathrm{H}$. Adamcik-Preusser zu Niederberg [44], about Josef Stefan, defended appropriately enough at the University of Vienna, was an invaluable asset.

\section{REFERENCES}

[1] Strnad, J., 1993, "Jožef Stefan: The Centenary of His Death,” Ljubljana.

[2] von Obermayer, A, 1893, "Zur Erinnerung an Josef Stefan,” Braumüller, Vienna, (translated by Dustin Marshall).

[3] Stefan, J., 1857, "Allgemeine Gleichungen für oscillatorische Bewegung,” Poggendorff's Annalen der Physik, 102, pp. 365-387.

[4] Jungnickel, C., and McCormmach, R., 1986, Intellectual Mastery of Nature: The Torch of Mathematics 1800-1870, University of Chicago, Chicago, p. 205.
[5] Boltzmann, L., 1905, “Josef Stefan,” Populäre Schriften, J.A. Barth, Leipzig, pp. 92-103 (translated by Kevin B. Homer).

[6] Greenburg, V.D., 1994, “'A Piece of the Logical Thread...': Freud and Physics," in Reading Freud's Reading, eds. S.L.Gilman, J. Birmele, J. Geller, V.D. Greenberg, NYU Press, New York, pp. 232-251.

[7] Burr, A.C., 1934, "Notes on the history of the thermal conductivity of gases," Isis, 21(1), pp. 169-186.

[8] Maxwell, J.C., 1860, "Illustrations of the dynamical theory of gases - Part I," "Parts II and III," Philosophical Magazine, 19, pp. 19-32, 20, pp. 21-37.

[9] Stefan, J., 1872, "Untersuchung über die Wärmeleitung in Gasen, Erste Abhandlung,” Sitzungsberichte der kaiserlichen Akademie der Wissenschaften, MathematischeNaturwissenschaftliche Classe, II Abtheilung, 65, pp. 45-69.

[10] Strnad, J., and Vengar, A., 1984, "Stefan's measurement of the thermal conductivity of air," European Journal of Physics, 5, pp. 9-12.

[11] Stefan, J., 1875, "Untersuchung über die Wärmeleitung in Gasen, Zweite Abhandlung,” Sitzungsberichte der kaiserlichen Akademie der Wissenschaften, MathematischeNaturwissenschaftliche Classe, II Abtheilung, 72, pp. 69-101.

[12] Loschmidt, J., 1870, "Experimental-Untersuchungen über die Diffusion von Gasen ohne poröse Scheidewände," Sitzungsberichte der kaiserlichen Akademie der Wissenschaften, Mathematische-Naturwissenschaftliche Classe, II Abtheilung, 61, pp. 367-380, 62, pp. 468-478.

[13] Maxwell, J.C., 1873, "On Loschmidt's experiments on diffusion in relation to the kinetic theory of gases," Nature, 8 , pp. 298-300.

[14] Boltzmann, L., 1905, "Zur Erinnerung an Josef Loschmidt,” Populäre Schriften, Barth, Leipzig, pp. 228-252 (translated by Dustin Marshall).

[15] Stefan, J., 1871, "Über das Gleichgewicht und die Bewegung, insbesondere die Diffusion von Gasgemengen," Sitzungsberichte der kaiserlichen Akademie der Wissenschaften, Mathematische-Naturwissenschaftliche Classe, II Abtheilung, 63, pp. 63-124.

[16] Mirovic, J., 1996, "Remarks upon the contributions of J. Stefan to the understanding of diffusion processes," International Journal of Heat and Mass Transfer, 39, pp. 218220.

[17] Bird, R.B., Stewart, W., Lightfoot, E.N., 1966, Transport Phenomena, Wiley, NY.

[18] Krishna, R., and Wesselingh, J.A., "The Maxwell-Stefan approach to mass transfer," Chemical Engineering Science, 52, pp. 861-911.

[19] Stefan, J., 1872, "Über die dynamische Theorie der Diffusion der Gase,” Sitzungsberichte der kaiserlichen Akademie der Wissenschaften, MathematischeNaturwissenschaftliche Classe, II Abtheilung, 65, pp. 323-363. [20] Stefan, J., 1878, "Über die Diffusion der Kohlensäure durch Wasser und Alkohol,” Sitzungsberichte der kaiserlichen 
Akademie der Wissenschaften, MathematischeNaturwissenschaftliche Classe, II Abtheilung, 77, pp. 371-409. [21] Stefan, J., "Über die Diffusion von Säuren und Basen gegeneinander," Sitzungsberichte der kaiserlichen Akademie der Wissenschaften, Mathematische-Naturwissenschaftliche Classe, II Abtheilung, 98, pp. 616-634.

[22] Stefan, J., 1873, "Versuche über Verdampfung," Sitzungsberichte der kaiserlichen Akademie der Wissenschaften, Mathematische-Naturwissenschaftliche Classe, II Abtheilung, 68, 385-423.

[23] Stefan, J., 1881, "Über die Verdampfung aus einem kreisförmig oder elliptisch begrenzten Becken," Sitzungsberichte der kaiserlichen Akademie der Wissenschaften, Mathematische-Naturwissenschaftliche Classe, II Abtheilung, 83, pp. 943-954.

[24] Fuchs, N.A., Evaporation and Droplet Growth in Gaseous Media, Pergamon, NY, 1959.

[25] Hicks, B.B., 2007, "Deposition of Atmospheric Acidity," in Atmospheric Acidity: Sources, consequences and abatement," eds. M. Radojevic and R.M. Harrison, Springer, pp. 178-180.

[26] Kalinchak, V.V., 2001, "Influence of Stefan Flow and Convection on the Kinetics of Chemical Reactions and Heat and Mass Exchange of Carbon Particles with Gases,” Journal of Engineering Physics and Thermophysics, 74 (2), pp. 323330.

[27] Gordon, A.R., Starodubov, L.S., and Zayavlin, V.R., 1978, "Question of Stefan flow in liquids," Journal of Engineering and Thermophysics, 34 (6), pp. 1059-1065.

[28] Prodi, F., Santachiara, G., and Cornetti, C., "Measurements of diffusiophoretic velocities of aerosol particles in the transition region,” Journal of Aerosol Science, 33 (1), pp. 181188.

[29] Wettlaufer, J.S., 2001, “The Stefan Problem: Polar Exploration and the Mathematics of Moving Boundaries," Festschrift 150 Jahre Institut für Met und Geophysik, Styria, Graz.

[30] Vuik, C., 1993, "Some historical notes on the Stefan problem,” Nieuw Archief voor Wiskunde, 4e serie, 11, pp. 157167.

[31] Lamé, G., and Clapeyron, E., 1831, "Mémoire sur la solidification par refroidissement d'un globe liquide," Annales de Chimie et de Physique, 47, pp. 250-256.

[32] Weber, H., 1901, Die partiellen Differential-Gleichungen der Mathematischen Physik, Vieweg, Braunshweig, p. 122.

[33] Stefan, J., 1889, "Über die Theorie der Eisbildung, insbesondere über die Eisbildung im Polarmeere,” Sitzungsberichte der kaiserlichen Akademie der Wissenschaften, Mathematische-Naturwissenschaftliche Classe, II Abtheilung, 98, pp. 965-983.

[34] Rubenstein, L.I., 1971, The Stefan Problem, AMS, Providence.

[35] Šarler, B., 1995, "Stefan's work on solid-liquid phase changes,” Engineering Analysis with Boundary Elements, 16, pp. 83-92.
[36] Lock, G.S.H., “On the use of asymptotic solutions to plane ice-water problems,” Journal of Glaciology, 8, pp. 285-300.

[37] Dulong, P.L., and Petit, A.T., "Des Reserches sur la Mesure des Températures et sur les Lois de la communicacion de la chaleur," Annales de Chimie et de Physique, 7, pp. 225264.

[38] Tyndall, J., 1865, Heat Considered as a Mode of Motion, Longman, Green, Longman, Roberts and Green, London.

[39] Stefan, J., 1879, "Über die Beziehung zwischen der Wärmestrahlung und der Temperatur,” Sitzungsberichte der kaiserlichen Akademie der Wissenschaften, MathematischeNaturwissenschaftliche Classe, II Abtheilung, 79, pp. 391-428. [40] Strnad, J., 1998, “On Stefan's radiation law,” researcher, Journal of Research and Innovation in Slovenia, 28.

[41] Crepeau, John C., 2007, “Josef Stefan: His life and legacy in the thermal sciences," Experimental Thermal and Fluid Science, 31, pp. 795-80.

[42] Worthing, A.G., and Halliday, D., 1948, Heat, Wiley, New York, pp. 226-227, 439.

[43] Dougal, R.C., 1979, “The centenary of the fourth-power law,” Physics Education, 14 (4), pp. 234-238.

[44] Adamcik-Preusser zu Niederberg, H., 2004, Die wissenschaftliche Bedeutung der physikalischen Arbeiten von Josef Stefan, doctoral dissertation, University of Vienna. 